\title{
Rancang Bangun Media Player Pada Layanan Aplikasi TV Streaming Program Studi Broadband Multimedia "PSBM TV"
}

\author{
Milatu Fadilah Cholii ${ }^{1}$, Agus Wagyana ${ }^{1}$
}

\begin{abstract}
Media player is a software that is used to play multimedia content. PSBM that is stands for Program Studi Broadband Multimedia is a player operates in the desktop, made to be able to display multimedia files and live tv broadcasts. This application is built using Visual Studio 2010 with the .Net programming language on Windows. The testing are about the function, performance and quality of the application. The results are successful according to the design. The performance evaluated by testing the test command on the functions of application using Testingwhiz. The Risk Based Testing method is used of the probability error that occurs with the impact of the error generated by the probability. It is show several risky functions, there are stream, browse, play, open, close, go, back and refresh buttons. A risky function is the core in an application that happen when exposed to an error, it will inhibit the performance of the application itself. Quality testing results based on ISO9216 standard (currently ISO-25010) about software quality showed that PSBM Player in the Medium category of 6 characteristics that influenced the quality with a questionnaire on 31 respondents. The data shows that the overall external quality of the PSBM Player is 0.35 which is in the Medium category and for Quality in Use of application isO.69 which is in the High category.
\end{abstract}

KEYWORDS: ISO-9216(Currently 25010), Media player, Risk Based Testing, Streaming, Visual Studio 2010

\begin{abstract}
ABSTRAK: Media player merupakan software yang digunakan untuk memutarkan sebuah konten multimedia. Aplikasi Program Studi Broadband Multimedia (PSBM) yang disebut PSBM Player ini dibuat untuk dapat menampilkan file multimedia serta siaran live televisi. Proses perancangan dan pembuatan menggunakan software Visual Studio 2010 dengan bahasa pemrograman .Net pada Windows. Pengujian aplikasi berupa pengujian fungsi, kinerja dan kualitas dari aplikasi. Hasil pengujian fungsi aplikasi berhasil sesuai dengan perancangan. Pengujian kinerja aplikasi dilakukan dengan menguji test command pada fungsi dalam aplikasi menggunakan software Testingwhiz. Perhitungan resiko fungsi dihitung dengan metode Risk Based Testing dari probabilias error yang terjadi dengan dampak error yang dihasilkan oleh probabilitas tersebut. Hasil pengujian yakni ada beberapa fungsi yang beresiko yaitu fungsi stream, browse, play, open, close, go, back dan refresh button. Fungsi yang beresiko tersebut merupakan fungsi inti pada aplikasi yang apabila terkena bug atau error akan menghambat kinerja dari aplikasi PSBM Player. Hasil pengujian kualitas berdasarkan standar ISO-9216 (saat ini ISO-25010) tentang kualitas software yakni PSBM Player masuk dalam kategori Medium dalam 6 karakteristik yang mendasari sebuah kualitas berdasarkan kuesioner pada 31 responden dengan pengolahan data menunjukan bahwa secara keseluruhan kualitas eksternal aplikasi PSBM Player ialah 0.35 yang termasuk ke dalam kategori Medium dan Quality in Use sebesar 0.69 di kategori High.
\end{abstract}

KATA KUNCI: ISO-9216 (Saat ini 25010), Media player, Risk Based Testing, Streaming, Visual Studio 2010.

\section{PENDAHULUAN}

Perkembangan teknologi telekomunikasi dan informasi dalam bidang penyiaran di dunia saat ini sudah mengalami kemajuan yang cukup pesat. Salah satunya ialah teknologi streaming,

streaming merupakan sebuah teknologi yang digunakan untuk memainkan sebuah file audio maupun video secara langsung maupun dengan pre-record yang berada di web server.

Saat ini, streaming sudah berkembang dan banyak digunakan oleh kalangan luas. Dengan adanya teknologi ini, maka client secara mudah dapat menyaksikan konten yang spesifik berdasarkan apa yang dibutuhkan, sehingga tercipta efektifitas dan efisiensi. Streaming dimanfaatkan pula dalam dunia pendidikan yang dipergunakan sebagai sarana edukasi dan pembelajaran yang sifatnya lebih modern, real time dan efisien serta dapat digunakan kapan saja dimana saja. Perancangan TV Streaming untuk Program Studi Broadband Multimedia (P S B M) Jurusan Teknik Elektro ini dimaksudkan agar mahasiswa dan juga pengajar dapat memanfaatkan internet khususnya teknologi streaming lebih jauh sehingga metode pembelajaran dapat menjadi lebih dinamis dan lebih mudah.

Streaming audio, video maupun data melalui internet merupakan suatu hal yang biasa dan banyak dilakukan oleh semua kalangan. Salah satu komponen inti dari sistem streaming ini diantaranya ialah media player. Media player berperan penting sebagai wadah bagi konten yang tersedia agar dapat diputar, disaksikan dan dinikmati oleh user. Selain berfungsi untuk memainkan konten berupa file audio video yang bersifat offline yaitu file yang ada pada library PC atau laptop, media player juga dapat memainkan sebuah tautan atau link yang berasal dari internet. Pada penelitian ini dirancang media player sebagai jembatan untuk menyaksikan layanan tv streaming tanpa membuka suatu browser.

\section{KAJIAN PUSTAKA}

PSBM TV merupakan sebuah layanan tv streaming berbasis web dan menggunakan aplikasi media player yang dirancang bangun untuk digunakan sebagai media pemutar konten sumber audio video yang tidak hanya berasal dari PC atau laptop namun juga tautan atau link atau juga URL dari tv streaming khususnya layanan web dari tv streaming "PSBM TV". Sehingga tidak hanya dapat digunakan untuk memainkan file audio dan video, user dapat menyaksikan tayangan streaming pada PC atau laptopnya tanpa membuka sebuah browser internet dengan bantuan koneksi internet. Aplikasi tv streaming "PSBM TV" yang disajikan pada web juga dirancang agar dapat dihubungkan pada tv analog melalui perangkat keras video sender dengan antena bowtie yang telah dimodifikasi agar aplikasi tv streaming "PSBM

${ }^{1}$ Politeknik Negeri Jakarta Jurusan Teknik Elektro Program Studi Broadband Multimedia 
TV" dapat disaksikan tidak hanya pada web namun juga pada tv analog.

Perangkat lunak yang digunakan untuk merancang bangun program aplikasi ini adalah Visual Studio 2010, dengan menggunakan bahasa pemrograman .NET. Program aplikasi ini dilengkapi dengan beberapa fitur menu yaitu Menu Default berupa Player dengan Create Playlist, Menu Live Streaming, Menu Browser dan Menu About

Pada Gambar 1, dijelaskan sistem aplikasi berupa diagram blok dimana media player akan menerima sumber berupa konten. Konten yang masuk dapat terdiri dari dua jenis, yaitu sumber online atau sumber offline. Sumber offline, yaitu konten multimedia berupa file dengan format yang mendukung untuk dimainkan pada player yang berupa beberapa format file seperti container, video coding format dan audio coding format yang tersimpan pada PC ataupun laptop. Kemudian sumber online merupakan sebuah tautan atau link maupun URL yang dimasukan dalam media player dengan menyalin tautan tersebut. Sehingga, media player akan memainkan dan menampilkan konten streaming tersebut tanpa perlu membukanya pada sebuah browser. Sumber online yang masuk akan dilakukan proses decoding terlebih dahulu, kemudian konten akan masuk ke renderer untuk dilakukan rendering sehingga menghasilkan sumber yang bersih dan siap diputar atau ditampilkan pada player. Dalam sisi player terdapat streaming engine yang merupakan modul pusat yang berinteraksi dengan decoder API, yang mendorong potongan-potongan media yang berbeda pada decoder dan menangangi switching serta playback-nya. Lalu dengan sedikit buffer atas hasil engine tersebut maka konten dapat disaksikan dan ditampilkan pada media player oleh user.

Perancangan aplikasi berupa ilustrasi media player yang diberi nama PSBM Player ini dapat dilihat pada Gambar 2. Terdapat tiga menu utama pada player yang dapat digunakan oleh user untuk keperluan di luar pemutaran file multimedia. Ketiga menu tersebut ialah Menu Live Streaming, Menu Browser dan Menu About. Untuk Menu Live Streaming dan Menu Bowser diperlukan sebuah koneksi internet yang digunakan untuk penghubung jaringan

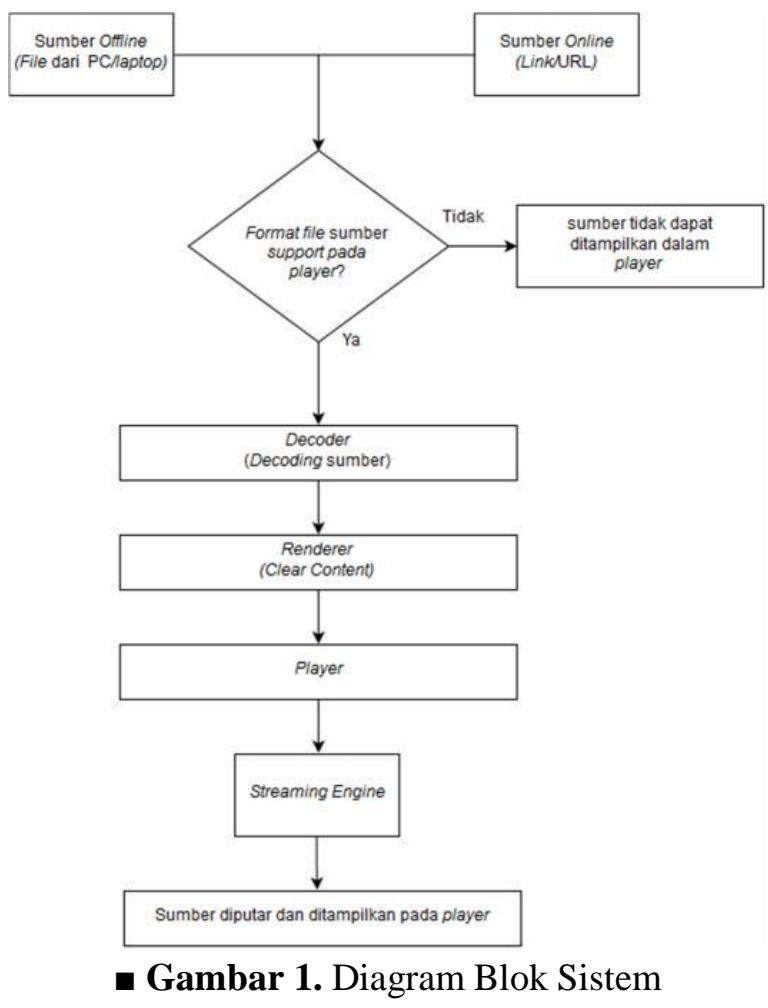




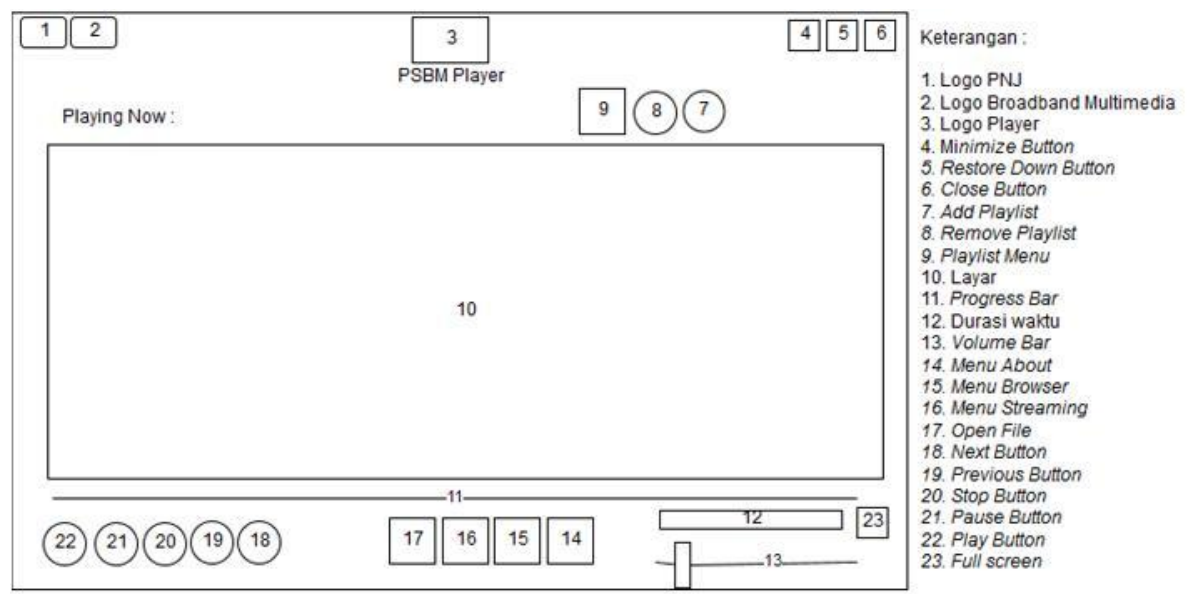

- Gambar 2. Ilustrasi Aplikasi Media Player PSBM Player

Cara kerja aplikasi media player PSBM Player ini dijelaskan pada alur dari Gambar 3. Pada Gambar 3. dijelaskan apabila aplikasi ini dijalankan, maka terdapat tampilan default yang akan muncul pertama kali, dalam tampilan ini terdapat beberapa fungsi yang bisa dijalankan dan dipilih oleh user. User dapat mem-playback suatu file ataupun menjalankan mode playlist ataupun memilih menggunakan tautan atau link dengan format file.M3U untuk menyaksikan tayangan televisi secara live. Dari fungsi playback terdapat beberapa control player yang digunakan untuk kontrol saat sebuah file dimainkan

\section{Video Streaming}

Video Streaming merupakan suatu layanan yang memungkinkan suatu server untuk menyiarkan suatu video yang bisa diakses oleh client-nya. File yang dikirim berupa rangkaian packet time-stamped yang disebut

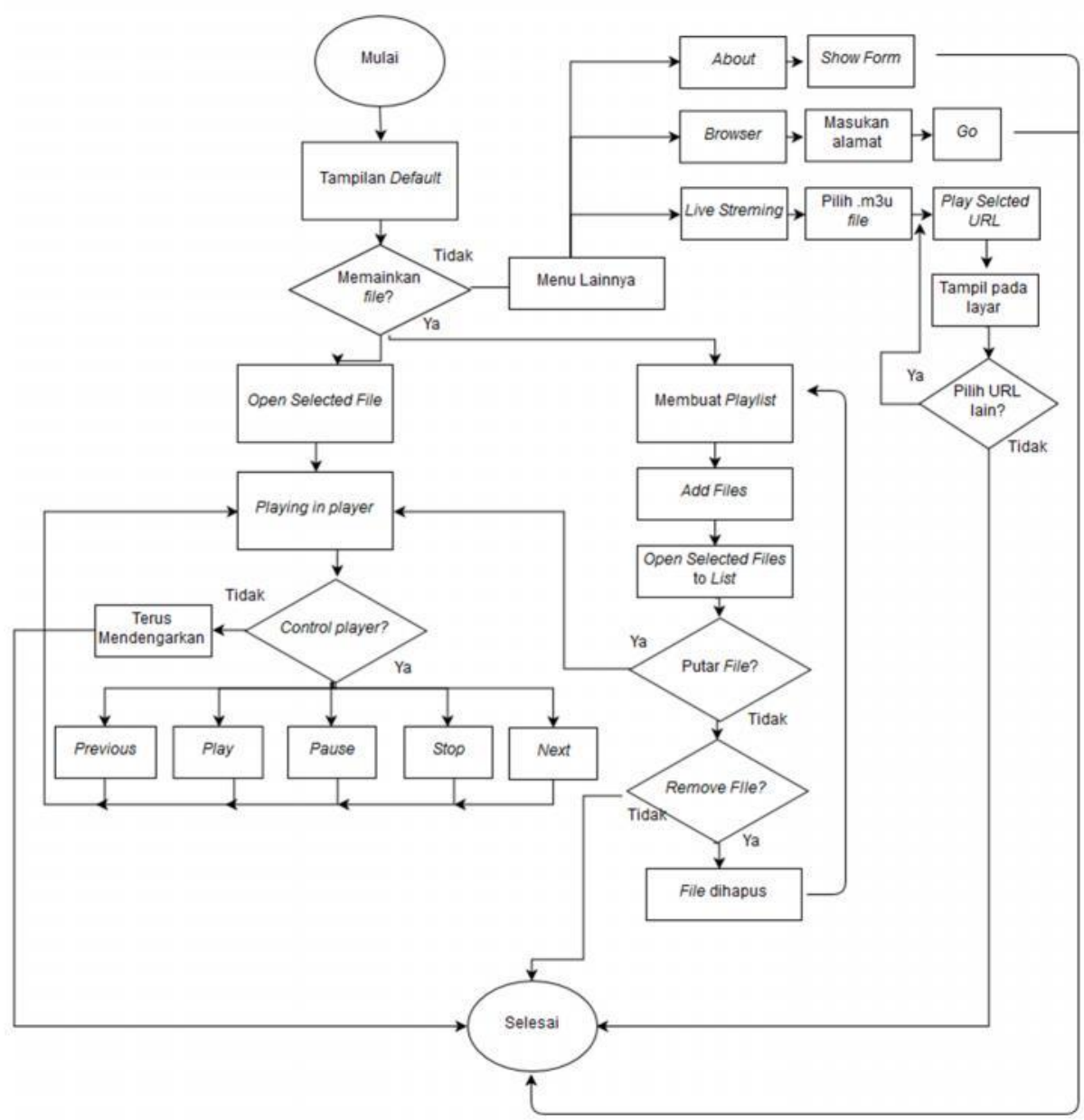

- Gambar 3. Flowchart Cara Kerja Aplikasi 
dengan stream. Kemudian pada sisi end user ataupun pengguna, file yang dikirimkan tersebut dapat segera dinikmati tanpa harus menunggu proses pengunduhan selasai karena file-nya terus mengalir tanpa interupsi. Layanan video streaming memungkinkan penggunanya untuk mengakses video secara real time ataupun video yang sudah direkam sebelumnya. Ide dasar dari streaming sebuah file multimedia yang berupa audio atau video diilustrasikan pada Gambar 4, ialah untuk membagi file tersebut ke dalam beberapa bagian, kemudian mentransmit-nya, sehingga receiver dapat men-decode dan memainkan file tersebut berdasarkan bagian-bagian file yang telah diterima tanpa harus menunggu keseluruhan dari file tersebut untuk disaksikan[1]

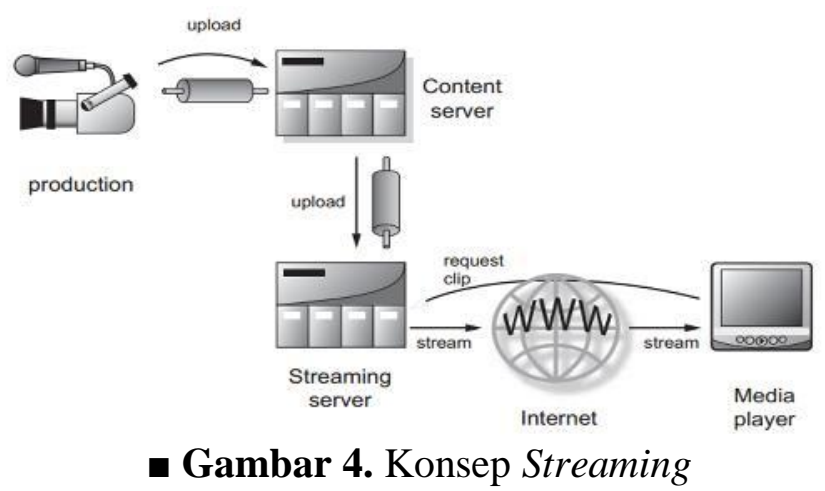

\section{Media Player}

Pemutar media atau media player adalah sebuah perangkat lunak komputer yang dapat memutarkan dan memainkan berkas media. Namun, media player biasanya dapat memainkan dan memutarkan kedua media atau file dari audio atau video tersebut dalam berbagai format atau jenis file yang didukung oleh player tersebut.

Media player merupakan media handler yang digunakan untuk rendering dan mengontrol data media yang berbasis waktu. Player memperluas controller interface. Player menyediakan metode untuk memperoleh komponen Abstract Window Toolkit (AWT), pemrosesan media kontrol dan cara untuk mengelola pengontrol lainnya.

Sebuah program komputer untuk memainkan file multimedia seperti video, film, atau audio. Aplikasi ini mampu membaca dan memutarkan tidak hanya satu tipe file melainkan banyak tipe atau ekstensi file. Pemutar media biasanya menampilkan ikon kontrol media standar seperti play, pause, fast forward, back forward, dan stop. Selain itu, pemutar media juga umumnya memiliki progess atau playback bar untuk menemukan posisi saat file diputarkan dalam durasi file media tersebut. Dalam Gambar 5, dijelaskan siklus hidup dari sebuah player yaitu[2] :

1. Unrealized State $\quad$ : Player tidak mengetahui media apa yang harus ditangani

2. Realizing State $\quad$ : Player mengidentifikasi dan memperoleh resource yang dibutuhkan utuk memutarkan media.

3. Perfetching State $\quad$ : Player menyempurnakan data media 


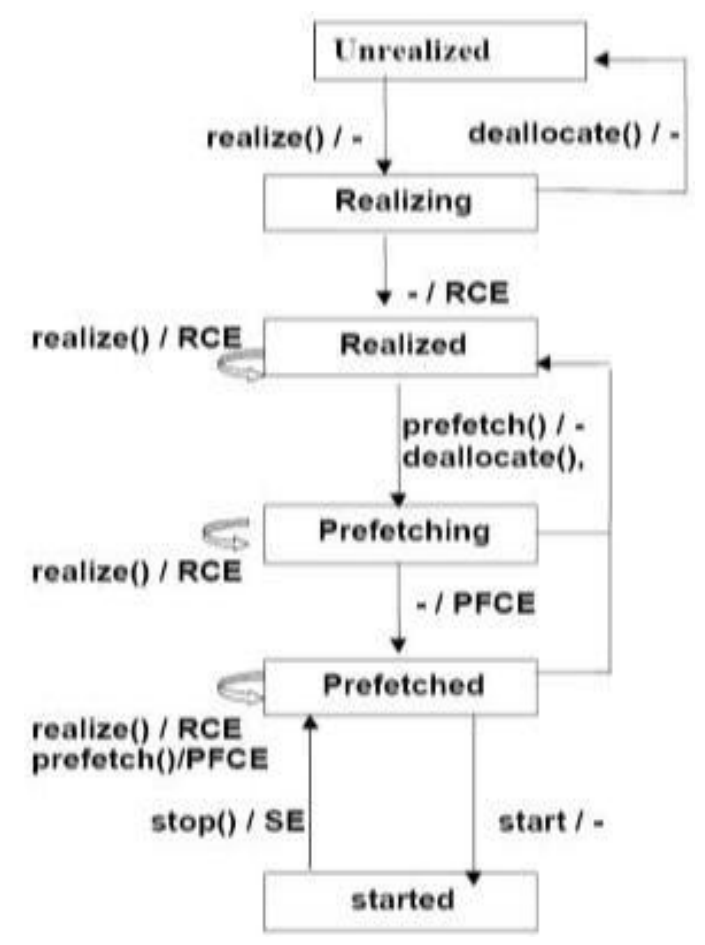

- Gambar 4. Konsep Streaming

\section{Risk Based Testing}

Resiko ialah produk dari probabilitas, bahwa sesuatu yang negatif, kegagalan akan terjadi dan biaya (kerusakan) dari konskekuensi yang kemudian pun akan terjadi. Resiko terdiri dari kerusakan (damage) dan kemungkinan dari kerusakan (probability).

Dalam penghitungan suatu resiko terdapat metode Risk Based Testing (RBT), RBT adalah proses pengujian dengan fitur unik. Pada dasarnya untuk proyek dari aplikasi atau perangkat lunak yang didasarkan pada resiko, pengujian yang dilakukan berbasis resiko dengan memprioritaskan dan menekankan tes yang sesuai pada saat pelaksanaan tes. Benda atau item dengan risiko tertinggi diuji terlebih dahulu dan lebih intensif daripada area dengan risiko rendah.[3] Dengan kata lain, resiko adalah peluang terjadinya hasil yang tidak diinginkan. Hasil yang tidak diinginkan ini juga terkait dengan dampak. Terkadang sulit untuk menguji semua fungsi dari suatu aplikasi atau bisa dibilang mungkin tidak mungkin. Penggunaan metode ini dilakukan untuk menguji fungsionalitas yang memiliki dampak dan kemungkinan kegagalan tertinggi

Metode RBT banyak digunakan oleh perusahaan dengan maksud untuk mengevaluasi perangakat lunak agar kualitas perangkat lunak menjadi jauh lebih baik. Perhitungan RBT ialah :

Risk factor $=$ Probability $\mathrm{x}$ Impact $\ldots$

Keterangan:

Probabity : Kemungkinan bug atau kesalahan yang terjadi

Impact : Tingkat kerugian yang akan terjadi ketika risiko ini terwujud

Skala nilai Probability dapat mengambil nilai 1 hingga 5. Dimana 1 adalah probabilitas kejadian akan menjadi rendah (error tidak mungkin terjadi sama sekali) dan 5 menjadi tinggi (error pasti akan terjadi). Demikian pula, Impact juga dapat diberi peringkat 1 hinga 5. Dimana 1 menjadi dampak rendah (bahkan jika risiko ini terwujud, kerugian minimum) dan 5 menjadi dampak tinggi (kerugian besar ketika terjadi

\section{Model Kualitas Eksternal}

Bagian pertama dari kualitas model tersebut menentukan 6 karakteristik yang mereka bagi kedalam 21 sub karakteristik untuk kualitas internal dan kualitas eksternal. Pada standar ISO-9126 (ISO/IEC 9126-1:2001) saat ini standar tersebut telah direvisi menjadi ISO/IEC 25010:2011 yang merupakan standar yang 
menjelaskan tentang kualitas dari sebuah perangkat lunak atau software. Dalam enam karakteristik yang dijadikan faktor kualitas yakni functionality, realiability, usability, efficiency, maintainability dan portability. Keenam faktor tersebut kemudian diolah dengan menggunakan pendekatan kuesioner terhadap responden yang kemudian hasil survey data diolah dijadikan sebagai data penunjang dari hasil kualitas eksternal dari aplikasi atau software yang dibuat yang berupa PSBM Player.

\section{Tampilan Awal Aplikasi}

Rancangan dari tampilan awal media player dapat dilihat pada Gambar 5. Tampilan awal ini merupakan tampilan yang akan muncul pertama kali untuk memainkan atau memutarkan konten berupa file video maupun audio. Dalam tampilan seperti ini, media player sudah dapat menjalankan fungsinya untuk memainkan dan memutarkan file yang tersimpan pada PC ataupun laptop secara langsung dengan menekan tombol 13 yaitu Menu Open Files. Serta dapat juga digunakan dengan membuat sebuah daftar lagu atau playlist seperti Gambar 3.5 di atas dengan menekan menu 3 dan untuk menambahkan atau menghapus file pada playlist dapat dilakukan dengan menekan tombol atau button 4 dan 5

Pada media player tersebut terdapat beberapa tombol atau button yang digunakan untuk menjalankan fungsi media player, serta untuk menampilkan fungsi lain yang ada pada player tersebut. Untuk realiasasi dari aplikasi media player ini dapat dilihat pada Gambar 6. Saat aplikasi berhasil diinstalasi pada desktop
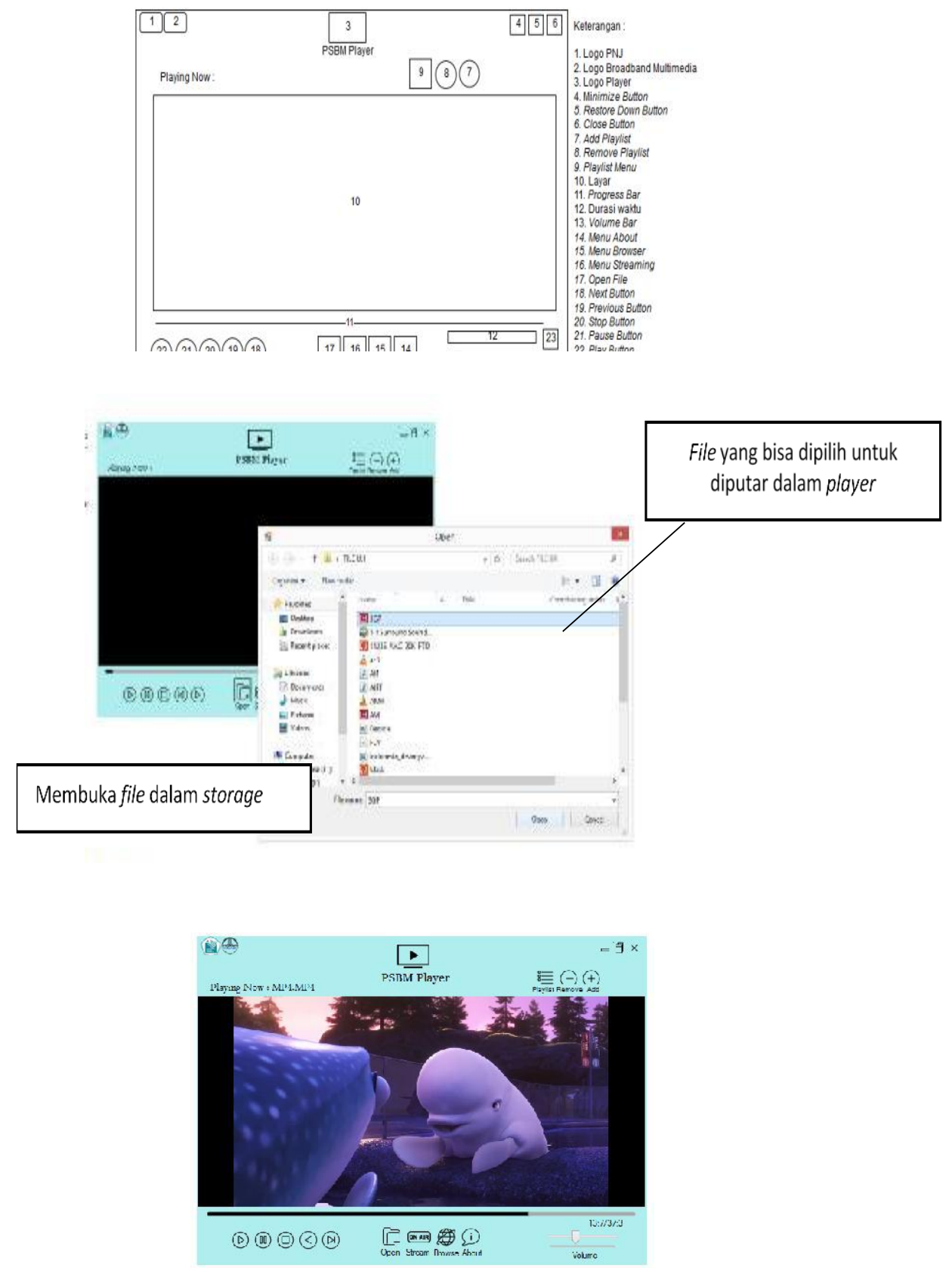

- Gambar 6. Realisasi Hasil Pengujian Aplikasi 


\section{Menu Live Streaming}

Pada Gambar 7. ditunjukan rancangan dari tampilan Stream Form pada media player yang muncul apabila user menekan tombol nomor 12 pada tampilan awal media player. Form ini digunakan untuk membuka tautan atau link atau URL dalam format .M3U yaitu sebuah daftar main atau playlist yang berisi beberapa tautan di dalamnya. Dalam kasus ini, tautan tersebut merupakan sebuah tautan siaran televisi dari kanal-kanal beberapa stasiun televisi lokal maupun internasional. Tautan yang telah dipilih sebelumnya menggunakan tombol Open File pada tombol nomor 5 pada Gambar 3.4 nantinya dapat di-klik dan output-nya berupa siaran langsung atau live dari stasiun televisi akan muncul pada layar media player di tampilan awal. Realisasi dari Menu ini dapat dilihat pada Gambar 8.

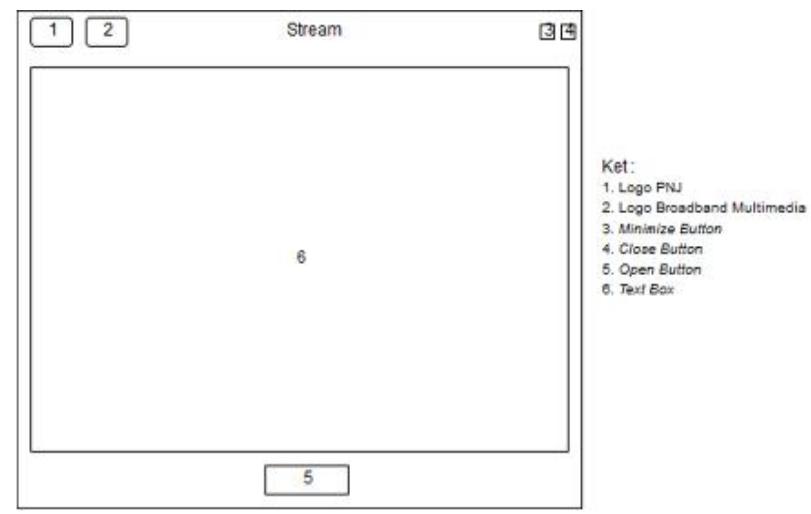

- Gambar 7. Rancangan Tampilan Menu Live Streaming

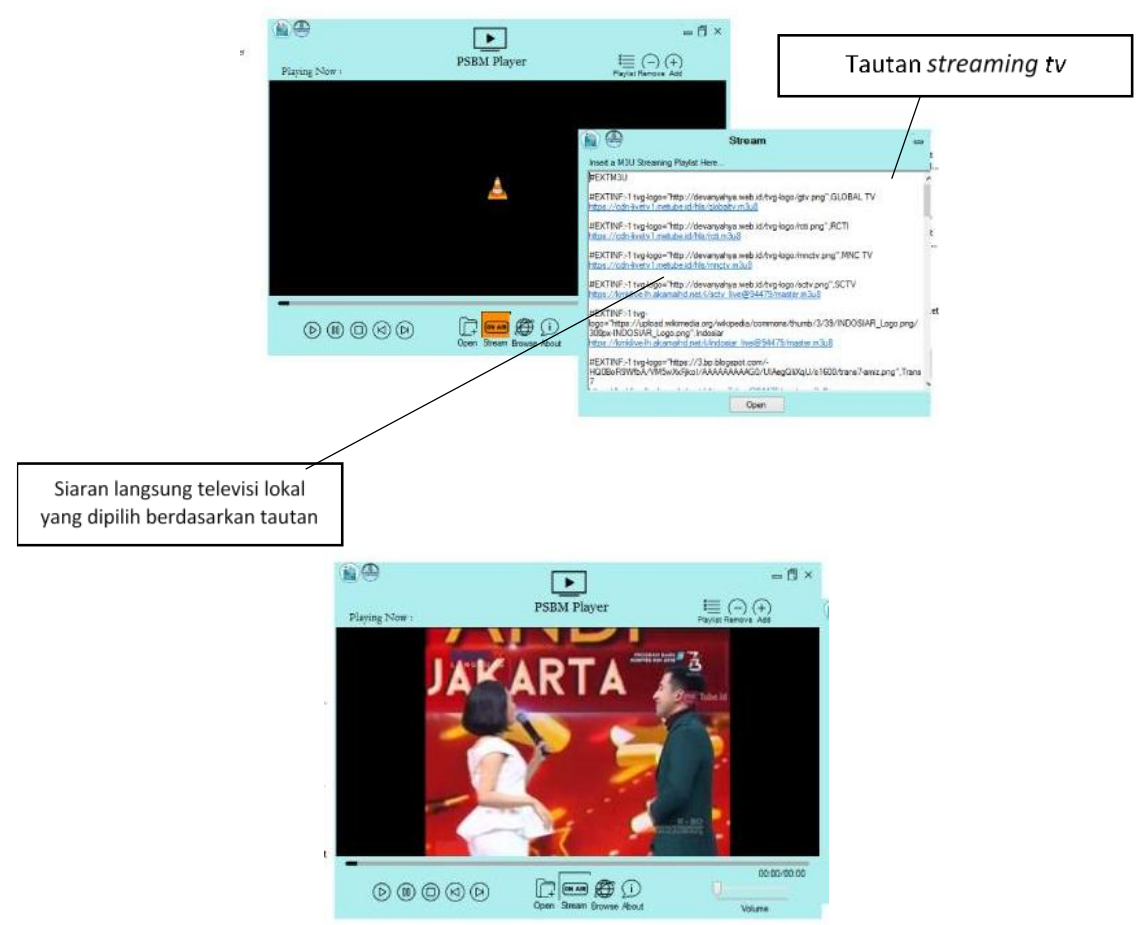

- Gambar 7. Realisasi Hasil Pengujian Menu Live

\section{Menu Browser}

Rancangan dari tampilan Browser Opener Form pada aplikasi media player ini ialah apabila user menekan tombol nomor 11 pada tamiplan awal media player maka tampilan ini akan muncul seperti pada Gambar 8. Form ini digunakan untuk menampilkan tautan atau link atau URL dari sebuah alamat website sehingga dapat diakses melalui media player. Dalam kasus ini, halaman web dari televisi streaming PSBM TV dapat diakses dan disaksikan melalui media player dengan koneksi jaringan internet. Tautan atau link atau URL dari sebuah website dapat diketik ataupun ditempel pada text box yang tersedia seperti pada nomor 7 dalam ilustrasi gambar dari tampilan awal media player, setelah itu tombol nomor 6 ditekan untuk mengkases halamn web tersebut. 
Tombol 8 dan 10 digunakan untuk kontrol, yaitu maju dan kembali, sedangkan tombol 9 berfungsi sebagai tombol refresh. Pada penggunaan aplikasi, untuk fungsi control tombol inti sebuah form seperti minimize, maximize dan juga close dapat dikendalikan dan digunakan oleh semua form dan menu pada aplikasi PSBM Player. Sehingga user dapat menggunakan aplikasi ini secara mudah dan efisien. Realisasi dari menu ini dapat dilihat pada Gambar 9

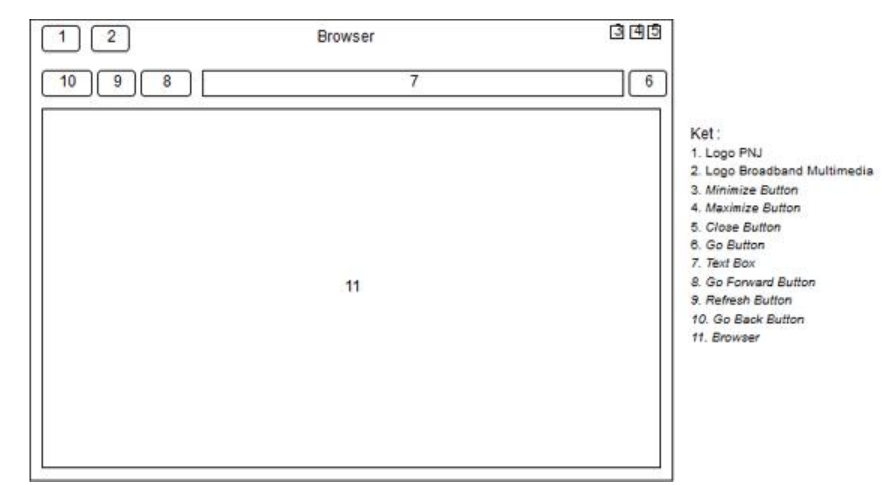

- Gambar 8. Realisasi Hasil Pengujian Menu Browser

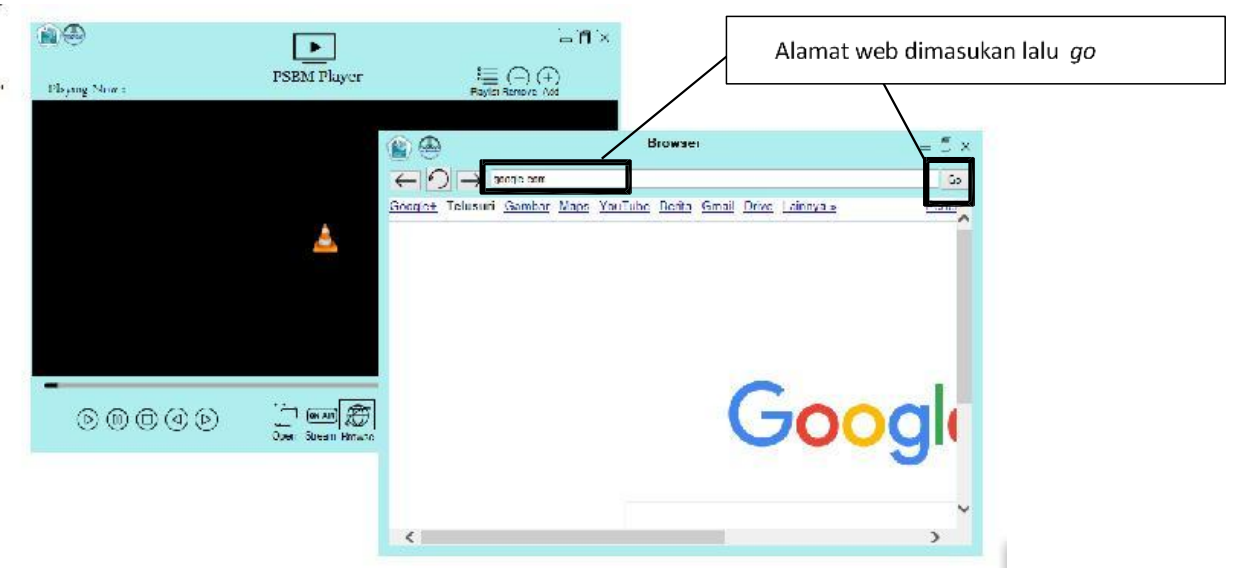

- Gambar 9. Realisasi Hasil Pengujian Menu Browser

\section{Menu About}

Pada Gambar 10. ditunjukan rancangan dari tampilan About Form pada media player apabila user mmenekan tombol 10 pada tampilan awal media player. Form ini digunakan untuk menampilkan informasi mengenai aplikasi seputar deskripsi dari aplikasi, cara kerja serta bantuan untuk pengoperasian tombol dan juga fungsi dari aplikasi sehingga user dapat menggunakan media player dengan mudah. Untuk hasil realisasi dari menu ini tampak pada Gambar 11.

HASIL PENGUJIAN DAN ANALISI

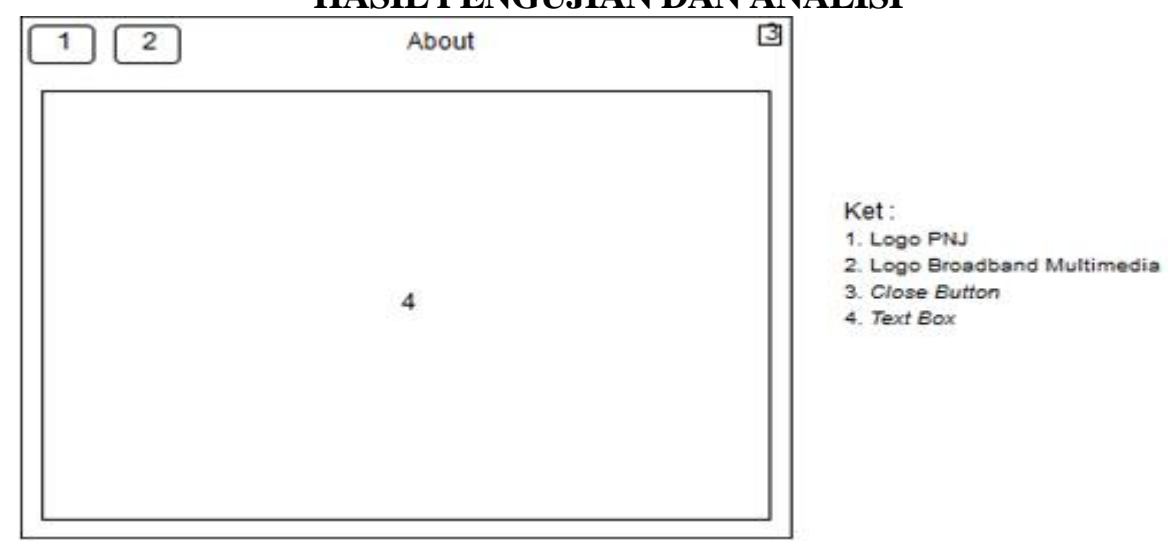

- Gambar 10. Realisasi Hasil Pengujian Menu About 


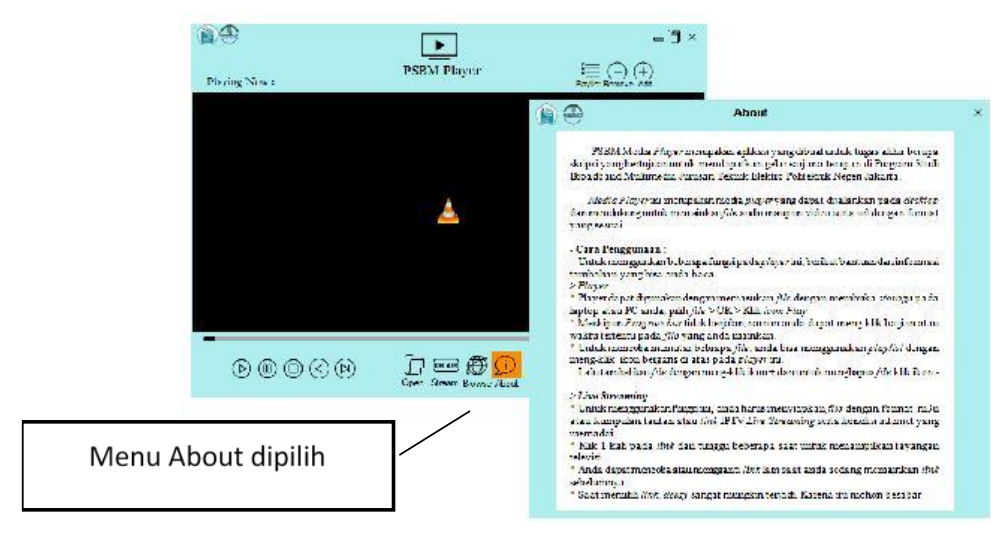

- Gambar 11. Realisasi Hasil Pengujian Menu About

\section{Pengujian Aplikasi PSBM Player}

Pengujian aplikasi PSBM Player bertujuan umtuk membuktikan apakah aplikasi dapat berjalan dengan baik sesuai dengan perancangan yang telah dibuat. Pada Tabel 1. menunjukkan deskripsi pengujian aplikasi PSBM Player.

- Tabel 1. Deskripsi Pengujian Aplikasi

\begin{tabular}{|c|c|c|}
\hline No. & Pengujian & Pengujia \\
\hline 1. & PSBM Player & $\begin{array}{l}\text { - Aplikasi dapat terpasang pada laptop administrator } \\
\text { - Aplikasi dapat terbuka dan menampilkan tampilan awal plaver }\end{array}$ \\
\hline 2. & Menu Player & $\begin{array}{l}\text { Aplikasi dapat memainkan dan memutarkan file } \\
\text { audio/video }\end{array}$ \\
\hline 3. & Menu Playlist & $\begin{array}{l}\text { - Aplikasi dapat menambah file yang terlebih dahulu dipilih } \\
\text { untuk dimasukan dalam playlist. } \\
\text { - Aplikasi dapat memainkan file yang berada pada playlist. } \\
\text { - Aplikasi dapat menghapus file yang telah dimasukan } \\
\text { Dalam playlist }\end{array}$ \\
\hline 4. & Menu Streaming & $\begin{array}{l}\text { - Aplikasi dapat memasukan file dengan format M3U pada } \\
\text { - } \quad \text { form streaming }\end{array}$ \\
\hline
\end{tabular}

\begin{tabular}{|c|c|c|}
\hline 5. & Menu Browser & $\begin{array}{l}\text { - Aplikasi dapat menampilkan siaran televisi lokal yang } \\
\text { berasal dari tautan dalam file M3U } \\
\text { Aplikasi dapat menampilkan situs website yang dituju } \\
\text { dengan mengisi alamat web pada box yang tersedia } \\
\text { - Aplikasi dapat menghubungkan situs web yang dituju } \\
\text { dengan button Go } \\
\text { - Aplikasi dapat mengembalikan tampilan halaman } \\
\text { web sebelumnya dengan button Back }(\leftarrow) \\
\text { Aplikasi dapat mengembalikan tampilan halaman } \\
\text { web selanjutnya yang telah diakses dengan tombol } \\
\text { Forward } \rightarrow \text { ) } \\
\text { Aplikasi dapat me-refresh halaman dengan button Refresh } \\
\text { (n) }\end{array}$ \\
\hline 6. & Menu About & $\begin{array}{l}\text { Aplikasi dapat menampilkan form yang berisi informasi } \\
\text { umum mengenai PSBM player dan fungsi-fungsinya }\end{array}$ \\
\hline
\end{tabular}

Hasil pengujian aplikasi PSBM Player dilakukan dengan menguji satu per satu menu yang ada pada player, yaitu Menu Player, Menu Streaming, Menu Browser dan Menu About. Setelah dilakukan instalasi dan pemasangan aplikasi 
pada laptop, pengujian menghasilkan bahwa semua fungsi pada menu dapat berfungsi dan berjalan sesuai dengan perancangan

\section{Pengujian Kinerja Aplikasi PSBM Player}

Pengujian kinerja aplikasi dengan melakukan test command pada fungsi dari aplikasi dengan menggunakan software Testingwhiz yaitu dengan menggunakan dua buah skenario pada Tabel 1. dan perhitungan (1).

Risk factor $=$ Probability $\mathrm{x}$ Impact.

- Tabel 2. Deskripsi Pengujian Aplikasi

\begin{tabular}{|c|c|c|c|}
\hline No & Tipe Skenario & Jenis Pengujian & $\begin{array}{c}\text { Perangakat yang } \\
\text { digunakan }\end{array}$ \\
\hline 1. & $\begin{array}{c}\text { Skenario 1 } \\
\text { (test command })\end{array}$ & Input Offline & $\begin{array}{c}\text { Laptop } \\
\text { Testingwhiz }\end{array}$ \\
2. & $\begin{array}{c}\text { Skenario 2 } \\
\text { (test command })\end{array}$ & Input Online & $\begin{array}{c}\text { Laptop } \\
\text { Testingwhiz } \\
\text { Modem }\end{array}$ \\
\hline
\end{tabular}

Hasil pengujian kinerja aplikasi menghasilkan suatu fungsi yang memilki resiko, untuk kedua skenario fungsi yang beresiko ialah fungsi dari Open, Play, Close, Stream, Browse, Go, Back dan Refresh Button. Hasil tersebut didapatkan dari perhitungan (1) dengan perhitungan dari metode Risk Based Testing yang menggunakan probabilitas dari fungsi yang jika error dan dampak yang terjadi apabila fungsi tersebut benar terkena error[4] kemudian diambil dari nilai risk yang tertinggi yang disebutkan dalam Tabel 3. dan Tabel 4.

Pengujian test command dilakukan dengan menggunakan software Testingwhiz Hasilnya, waktu durasi yang dihasilkan pada pengujian file offline dengan 3 file sekaligus yaitu WMA, 3GP dan AMR lebih stabil dan singkat yaitu 0,2 sekon dibanding dengan pengujian file online dengan 3 buah link dengan durasi sebesar 12 sekon dikarenakan file online menggunakan koneksi internet yang membutuhkan suatu pembentukan hubungan sehingga terjadi lama waktu atau durasi yang cukup lama

- Tabel 3. Hasil RBT File Offline

\begin{tabular}{|c|c|c|c|}
\hline Fung & Probabilit & Impact & Ris \\
\hline Open Button & 2 & 5 & 10 \\
Play Button & 2 & 5 & 10 \\
Pause Button & 2 & 4 & 8 \\
Stop Button & 2 & 4 & 8 \\
Volu & 2 & 3 & 6 \\
Menu About & 2 & 2 & 4 \\
Progress Bar & 3 & 3 & 9 \\
Minimize & 2 & 2 & 4 \\
Full Screen & 2 & 3 & 6 \\
Close Button & 2 & 5 & 10 \\
Playli & 4 & 2 & 8 \\
Next Button & 2 & 2 & 4 \\
Previous Button & 2 & 2 & 4 \\
\hline
\end{tabular}

- Tabel 4. Hasil RBT File Online

\begin{tabular}{|c|c|c|c|}
\hline Fung & Probabilit & Impact & Ris \\
\hline Stream Button & 4 & 5 & 20 \\
Minimize & 2 & 2 & 4 \\
Full Screen & 2 & 2 & 4 \\
Close Button & 2 & 5 & 10 \\
Browser & 4 & 5 & 20 \\
Go Button & 2 & 5 & 10
\end{tabular}




\begin{tabular}{|c|l|l|l|}
\hline Refresh Button & 2 & 4 & 8 \\
Back Button & 2 & 4 & 8 \\
\hline
\end{tabular}

\section{Pengujian Kualitas Aplikasi PSBM Player}

Pengujian kualitas aplikasi menggunakan standar ISO-9216 (saat ini ISO/IEC 25010 tahun

2011) mengenai kualitas suatu perangkat lunak berdasarkan beberapa aspek yang berkaitan dengan perangkat lunak tersebut. Pengujian ini dilakukan dengan meneliti tanggapan dari 31 Responden yang bersedia mencoba dan menggunakan PSBM Player dengan mengisi form kuesioner yang disediakan.

Hasil pengujian kualitas berdasarkan karakteristik responden yang menggunakan PSBM Player bahwa responden perempuan lebih banyak menggunakan aplikasi ini dibandingkan dengan laki-laki dengan jumlah persentase $74,21 \%$ sebanyak 23 orang perempuan dan persentase $25,8 \%$ sebanyak 8 orang laki-laki pada Gambar 12 dan sebanyak $67.7 \%$ didominasi oleh responden umur

21-26 tahun sebanyak 21 orang. Responden dengan umur 16-21 tahun berada di urutan kedua dengan persentase $25,8 \%$ sebanyak 8 orang, dan responden yang memiliki umur lebih dari 27 tahun sebanyaj 6,5\% yaitu 2 orang. Sedangkan

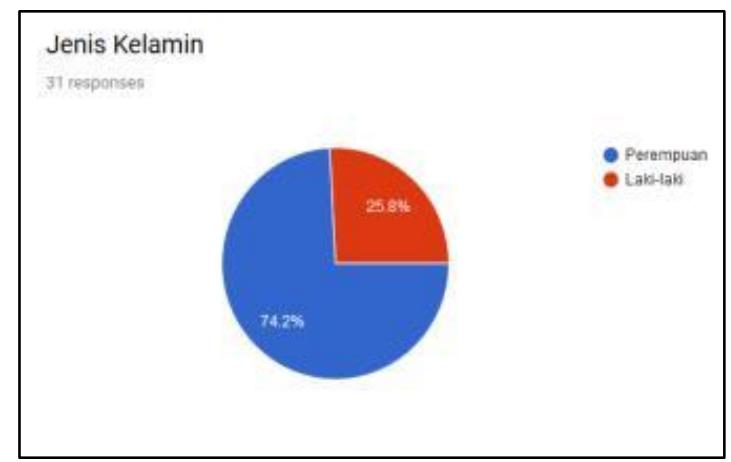

- Gambar 12. Hasil Karakteristik Responden Berdasarkan Jenis Kelamin

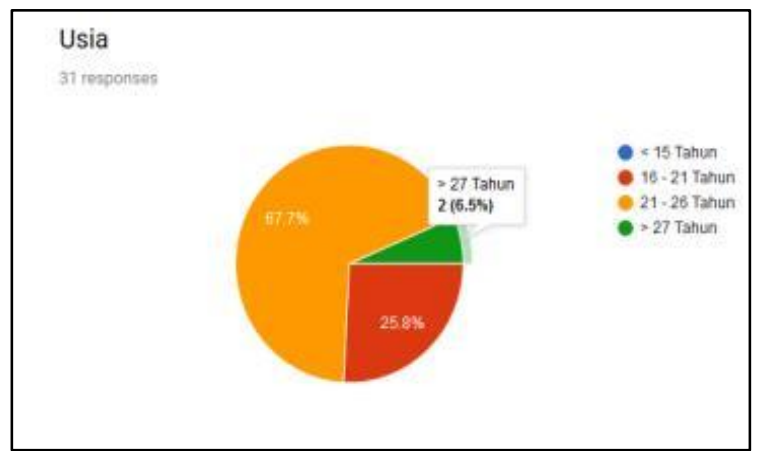

- Gambar 13. Hasil Karakteristik Responden Berdasarkan Usia

untuk responden dengan umur kurang dari 15 tahun tidak terhitung yang berkaitan dengan jenis kelamin dan Gambar 13 yang berkaitan dengan usia Berdasarkan hasil kedua karaktersitik tersebut ialah, saat ini, penggunaan media player tidak terbatas untuk kalangan tertentu, rentang usia yang beragam menunjukan bahwa media player menjadi suatu aplikasi yang bisa digunakan oleh usia berapapun dan siapapun laki-laki ataupun perempuan.

\section{Tanggapan Responden pada Kualitas Eksternal}

Dalam standar ISO 9126 (saat ini 25010) terdapat 5 faktor inti mengenai kulaitas perangkat lunak[5], berdasarkan hasil penenelitan melalui kuesioner didapatkan hasil : 


\section{Faktor Funcionality}

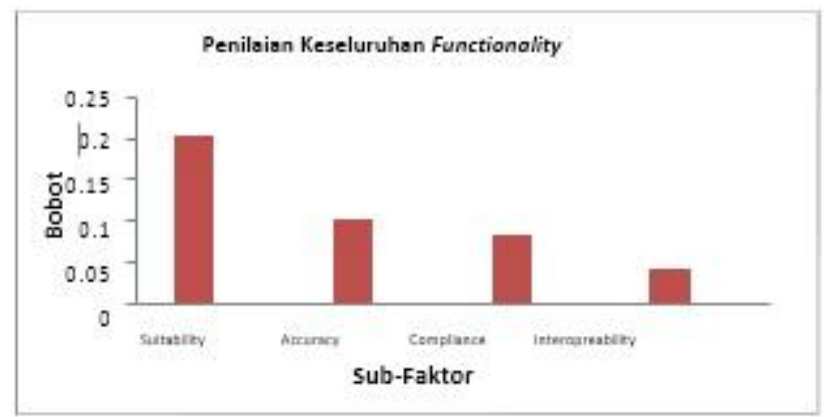

- Gambar 13. Hasil Faktor Functionality

Berdasakan Gambar 14. didapatkan hasil bahwa dari segi fungsionalitas keseluruhan aplikasi ini berada pada nilai 0.42 yang mana nilai yang baik yaitu mendekati angka 1 PSBM Player cukup dalam menyediakan kebutuhan user, diantaranya fungsi dalam menu player yang tersedia untuk memutarkan konten multimedia berupa video atau audio dan jumlah error yang terjadi masih dalam batas kewajaran yang diakibatkan oleh adanya bug, ketepatan fungsi atau menu pada aplikasi sesuai dengan script yang telah dibuat sehingga button atau menu bisa berjalan dengan baik

\section{Faktor Efficiency}

Pada faktor ini aplikasi didapatkan nilai sebesar 0.28 yang berarti dalam angka paling baik adalah 1 , dalam segi ini PSBM Player kurang efisien. Hal ini terjadi karena adanya delay dan juga bug yang menyebabkan aplikasi kurang maksimal dalam perfomansinya.

\section{Faktor Usability}

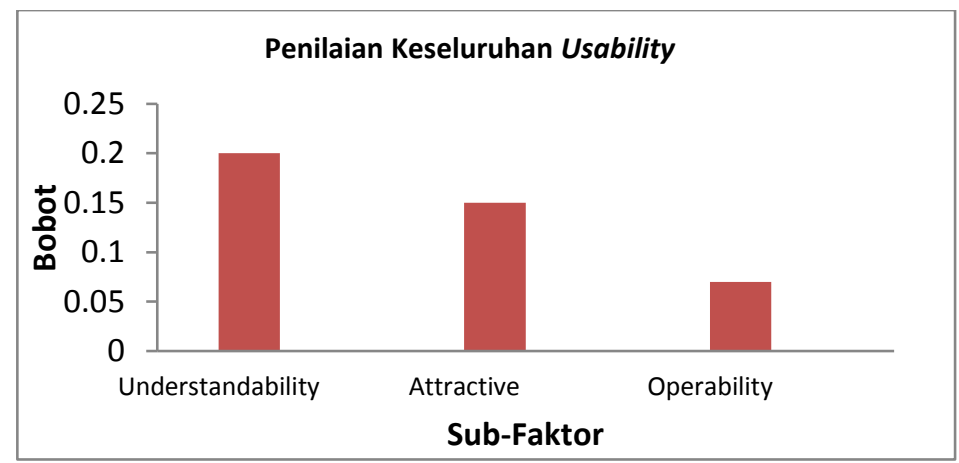

Gambar 15. Hasil Faktor Usability

Hasil dari segi kegunaan aplikasi keseluruhan yaitu dengan nilai 0,42 yang berarti cukup pada rentang paling baik adalah angka 1. Dari data tersebut, PSBM Player cukup untuk dipahami mengenai menu dan button yang tersedia, cukup saat digunakan dan menarik hati user diantaranya ketika digunakan dalam menyaksikan konten multimedia dan streaming, aplikasi PSBM Player cukup mudah untuk dioperasikan berdasarkan fungsi dan menu yang tersedia. Juga tampilan player yang cukup menarik.

\section{Faktor Maintainability}

Pada faktor ini dapatkan hasil dari segi pemeliharaan aplikasi secara keseluruhan didapatkan nilai 0.44 yang berarti cukup dari nilai yang paling baik ialah mendekati angka 1. Dari data tersebut, PSBM Player cukup mampu dalam modifikasi fungsi yaitu kemampuan untuk menggunakan lebih dari satu fungsi yang ada. Sehingga user dapat menggunakan fungsi lain selain untuk memutarkan konten audio atau video secara offline, seperti menggunakan fungsi тепи About atau menu Browser.

\section{Faktor Portability}

Gambar 16. didapatkan hasil dari segi portabilitas pada secara keseluruhan yaitu 0,45 yang berarti cukup dari nilai yang paling baik ialah mendekati angka 1. Berdasarkan data tersebut, PSBM Player cukup mudah untuk dipindahkan dari 
satu lingkungan komputer ke lingkungan yang lain. Dalam proses penginstalan juga tidak memakan banyak waktu dan tidak rumit.

\section{KESIMPULAN}

Berdasarkan hasil dan data dan analisa dari pengujian penelitian dari kinerja, kualitas dari aplikasi, dapat disimpulkan bahwa Aplikasi PSBM Player yang dapat berfungsi dan berjalan dengan baik. Kinerja fungsi dari aplikasi PSBM Player memiliki fungsi yang beresiko yang berarti fungsi tersebut merupakan fungsi inti dan krusial dari aplikasi serta penggunaan menu online seperti streaming dan browsing memerlukan durasi yang cukup lama disebabkan oleh konektivitas dari internet. Kualitas aplikasi Berdasarkan analisa dari penelitian dan pengumpulan form kuesioner untuk pengujian kualitas aplikasi PSBM Player didapatkan hasil bahwa apliaksi PSBM player termasuk kategori medium atau cukup dengan nilai akhir atau keseluruhan 0,35 untuk kualitas eksternal dan 0,69 dalam nilai terbaik mendekati angka 1 pada quality in use berdasarkan standar dari ISO-9126 (yang kini telah direvisi menjadi ISO/IEC 25010 pada tahun 2011) tentang sytems and software Quality Requirements and Evaluation (SQuaRE) -- System and software quality models

\section{DAFTAR PUSTAKA}

[1] Apostolopoulos, J. G., et al. 2002. Video Streaming: Concepts, Algorithms, and Systems.HP Laboratories, Palo Alto.

[2] Hayder, M. 2010. Design and Implementation of Java Media Player. Journal of Kerbala University. Vol 8.

[3] Veenendaal, E. 2011. Practical Risk-Based Testing Product Risj Management : The Prisma Method. Manchester, UK.

[4] Bach, James. 1999. Heuristic Risk-Based Testing. Software Testing and Quality Engineering Magazine. 11/99.

Internet : http://www.satisfice.com/articles/hrbt.pdf [7 Agustus 2018]

[5] International Organization for Standardization. ISO/IEC 9126-1:2001, ISO/IEC25010

Tahun 2011.

Internet : https://www.iso.org/standard/35733.html [16 Juli 2018] 